\title{
FORMAÇÃO INICIAL DE PROFESSORES NO ENSINO SUPERIOR: ESTRATÉGIAS DIDÁTICO-PEDAGÓGICAS INTERDISCIPLINARES
}

\author{
Maria Estela Lacerda Ferreira \\ (Dhttps://orcid.org/0000-0001-5263-6279
}

Daniela Melaré Vieira Barros ${ }^{2}$

(Dhttp://orcid.org/0000-0002-1412-2231

Resumo: O objetivo deste artigo é apresentar um estudo sobre as estratégias didáticopedagógicas utilizadas na formação inicial de professores e identificar se essas estratégias apresentam uma perspectiva interdisciplinar. A pesquisa foi realizada em um curso de Pedagogia de um Instituto Superior de Ensino. Pelas características da pesquisa, optou-se por uma metodologia qualitativa, um estudo de caso etnográfico. Foram observadas as aulas de três componentes curriculares específicos e aplicados 38 questões para os estudantes do último semestre do curso. Os dados obtidos indicam as estratégias que os estudantes preferem; a relação existente entre estratégia e aprendizagem; que os professores não utilizam, intencionalmente, estratégias didático-pedagógicas interdisciplinares, mas há evidências de que os futuros professores, espontaneamente, estabelecem relações não sistematizadas com os conhecimentos já desenvolvidos pela disciplina.

Palavras-chave: Interdisciplinaridade. Estratégias didáticas. Formação de professores.

1 Mestre em Supervisão Pedagógica- Universidade Aberta de Portugal. Atualmente é professora do Curso de Pedagogia do Instituto Singularidade. E-mail: mestela.ferreira@terra.com.br

2 Pedagoga, Especialista em Administração em Educação a Distância, Mestrado em Engenharia das Medias para a Educação Euromime- Erasmus Mundus- Portugal, Espanha e França, Mestrado em Educação pela UNESP- BRASIL, Doutorado em Educação UNESP -BRASIL, Pós-Doutorado pela UNICAMP e a UNED, segundo Doutorado pela UNED de Madrid, Professora Auxiliar DEED - Departamento de Ensino e Educação a Distância. Universidade Aberta de Portugal. E-mail: daniela.barros@uab.pt 


\section{BACHELOR OF EDUCATION: INTERDISCIPLINARY PEDAGOGICAL TEACHING STRATEGIES}

Abstract: The current work investigates pedagogical didactic strategies for teacher's initial education. In parallel, it identifies whether these strategies present an interdisciplinary perspective. The research was carried out in a Pedagogy Course from a College located in São Paulo city. Given the research characteristics, a qualitative methodology was chosen, namely an ethnographic case study. Three different classes from three different subjects were observed and 38 questionnaires were applied to students in their last term. The data obtained indicates which strategies students prefer and the justifications show the relation between strategy and learning. The data also indicates that teachers do not intentionally use interdisciplinary pedagogical didactic strategies, but there is evidence that future teachers spontaneously establish non systemic relations to previous knowledge already addressed by the discipline.

Keywords: Interdisciplinary perspective. Didactic strategies. Bachelor of education.

\section{LA FORMACIÓN INICIAL DE PROFESORES: ESTRATEGIAS DIDÁCTICO-PEDAGÓGICAS INTERDISCIPLINARES}

Resumen: El objetivo de este artículo es presentar un estudio sobre las estrategias didácticopedagógicas utilizadas en la formación inicial del profesorado e identificar si estas estrategias presentan una perspectiva interdisciplinar. La investigación se llevó a cabo en un curso de Pedagogía de un Instituto de Educación Superior. Por las características de la investigación, se eligió una metodología cualitativa, un estudio de caso etnográfico. Se observaron las clases de tres componentes curriculares específicos y se aplicaron 38 preguntas a los alumnos del último semestre del curso. Los datos obtenidos indican las estrategias que prefieren los alumnos; la relación entre la estrategia y el aprendizaje; que los profesores no utilizan intencionadamente estrategias didáctico-pedagógicas interdisciplinares, pero hay evidencias de que los futuros profesores establecen espontáneamente relaciones no sistematizadas con los conocimientos ya desarrollados por la disciplina.

Palabras-clave: Interdisciplinaridad. Estrategias didácticas. Formación inicial docente. 


\section{Introdução}

Este estudo tem como cenário um curso de Pedagogia - formação inicial de professores em um Instituto Superior de Ensino - ISE. Participaram da pesquisa estudantes do 60 semestre, três professores que trabalhavam com esses alunos, sendo que um dos professores é também a autora do estudo realizado, relatado agora neste texto. O estudo foi realizado com o consentimento da coordenação do curso e dos professores que colaboraram com a pesquisa, permitindo que suas aulas fossem observadas. No caso dos professores participantes, todos possuem mestrado e experiência na docência do Ensino Superior. Nas reuniões semanais de formação, o coletivo de professores se reunia para discussão de assuntos pedagógicos e curriculares, rendimento dos estudantes, dinâmica dos grupos, questões comportamentais dos alunos e outros temas diversos. Nessas reuniões, a autora deste estudo era um dos participantes, enquanto professora da instituição. Com frequência, aconteciam nos encontros relatos informais de atividades desenvolvidas pelos professores, fossem de forma individual ou em grupos, compostos por professores de disciplinas diferentes. Situações semelhantes a esta contribuíram para a motivação desta pesquisa, conforme será detalhado em seguida e, posteriormente, ao serem apresentados a metodologia adotada e os instrumentos utilizados para a coleta de informações.

Sabe-se que uma pesquisa nasce de observações, escutas e reflexões que no primeiro momento parecem triviais, mas podem ganhar força, forma e significado com o passar do tempo. A motivação para este estudo nasceu do entrelaçamento desses três aspectos - observação, escuta e reflexões - sobre:

I. inquietações da pesquisadora - sobre a aprendizagem, oriundas de seu tempo de docência no Ensino Fundamental, traduzidas na observação do tempo que o estudante passa na Educação Básica, em contato com conteúdos disciplinares de natureza diversa, que, se não forem acionados ou não constituírem um saber significativo, serão descartados pela memória. Será possível, durante o tempo 
escolar, construir nos aprendizes uma estrutura cognitiva formada por conceitos, procedimentos e habilidades, capaz de "ancorar" os saberes disciplinares, facilitando a transposição desses saberes para diferentes áreas do conhecimento e/ou construindo novos saberes?

II. comentários gerais e espontâneos dos estudantes do curso de Pedagogia, ouvidos com frequência pela pesquisadora (autora do texto) e aqui reproduzidos: "Nós já vimos este conteúdo na disciplina do professor X"; "Por que vocês [professores] não juntam as propostas das atividades? Pois temos que fazer mais de uma vez a mesma coisa"; ou "Na aula Y aprendemos este conteúdo"; "É outra coisa perceber que as disciplinas se conversam".

III. vozes formais de professores, do mesmo curso de Pedagogia, de diferentes disciplinas, relatando atividades desenvolvidas em conjunto e nomeando essas atividades como "projeto interdisciplinar" e/ou projeto integrado, justificando a nomenclatura pelo fato de as atividades apenas terem sido planejadas em conjunto, incluindo o mesmo instrumento de avaliação aplicado para as disciplinas envolvidas, e a correção das atividades, pelo olhar de cada professor em relação aos objetivos da sua disciplina.

Esses aspectos se entrelaçaram, impulsionaram a motivação para este estudo, auxiliaram a definir o tema - Estratégias didático-pedagógicas interdisciplinares, e os objetivos:

- Identificar se as estratégias didático-pedagógicas utilizadas pelos professores formadores contribuem para uma aprendizagem com perspectiva interdisciplinar. - Identificar se as estratégias escolhidas e aplicadas pelos professores formadores desenvolvem nos futuros professores habilidades de relacionar, com autonomia, os conhecimentos desenvolvidos nas diferentes disciplinas, colaborando para um rompimento das fronteiras disciplinares.

Definidos os objetivos, selecionaram-se duas perguntas: 
-Quais são as principais estratégias didático-pedagógicas interdisciplinares utilizadas pelos professores formadores na formação inicial docente?

-Quais são as ações e as estratégias didático-pedagógicas que possibilitam a construção de um pensamento interdisciplinar, um fio condutor que ligue conteúdos que, aparentemente, circulam em paralelo?

Tinha-se por hipótese que, trabalhando com a interdisciplinaridade, crianças e jovens teriam mais facilidade na transferência de aprendizagens de um campo de conhecimento a outro. A educação interdisciplinar capacita as crianças (futuros adultos) a enfrentar problemas, transcendendo os limites disciplinares para encontrar soluções e propostas adequadas, circulando entre diferentes campos do conhecimento. Pensamos que essas habilidades são necessárias no presente e serão também no futuro próximo.

As características do problema a ser investigado e a natureza das perguntas definiram a metodologia da investigação. No estudo em questão, foi adotada a etnografia, que se insere na abordagem qualitativa de investigação, pois entende-se que esta metodologia de pesquisa é um caminho adequado para tentar responder às perguntas propostas. A etnografia é a tentativa de descrição de uma cultura, ${ }^{3}$ e sua principal preocupação é o significado que têm as ações e os eventos para as pessoas, alguns diretamente expressos pela linguagem e outros transmitidos indiretamente, por meio das ações (ANDRÉ, 1995, p. 19).

O estudo utilizou, como técnicas para coletar os dados, a observação direta do cotidiano escolar e dos espaços e momentos em que o ensino e a aprendizagem formais aconteciam nas aulas dos professores participantes (incluindo as aulas da autora do estudo); a aplicação de um questionário aos estudantes do 6ㅇ semestre.

No enquadramento teórico, Zabala (1998); Fazenda (2004); Santomé (1998); Mangain, Dufour e Fourez (2002); Anastasiou e Alves (2009); Roldão (2009); Lenoir e Hasni (2016) auxiliaram a fundamentar os conceitos de interdisciplinaridade e de estratégia, evidenciando as dúvidas, as certezas, as contradições existentes na prática,

\footnotetext{
3 A instituição possui uma cultura própria, e seu Projeto Político-Pedagógico expressa suas crenças, concepções e princípios educacionais.
} 
estruturando o diálogo com os resultados, bem como as condições institucionais necessárias para uma prática interdisciplinar.

\section{Desenvolvimento}

Para iniciar o cenário teórico, apresenta-se o pensamento de Echeverría (2015, p. 7), ao defender que, na sociedade da informação, a aprendizagem precisará ser permanente, pois novos trabalhos e competências irão surgir, "as barreiras entre as profissões e titulações irão ficando difusas, tendendo-se à interdisciplinaridade e à cooperação entre pessoas de diversas formações, as quais formarão equipes mistas". Este autor prevê que o conteúdo curricular na escola do futuro será reduzido, com ênfase na "relação significativa entre saberes e formas de conhecimento muito diversos" (ECHEVERRÍA, 2015, p. 7). O aprendiz deverá ser "elaborador ativo das estratégias que lhe permitam descobrir as possíveis explicações para um fenômeno, fato ou acontecimento". (ECHEVERRÍA, 2015, p. 7) Em um mundo complexo, a autonomia de aprender a aprender, de saber buscar, nos diferentes campos do conhecimento, soluções criativas, inovadoras, mas eficazes, será uma habilidade necessária a desenvolver-se nos sujeitos.

Complementa-se a base teórica inicial com Amador (2015), ao indagar: será possível, na diversidade e singularidade das disciplinas presentes no currículo de formação inicial de professores, estabelecer uma comunicação entre campos aparentemente divergentes, traçar linhas transversais e desestabilizar aquilo que a razão moderna não quer admitir? Como romper o território de cada disciplina em direção à estrutura íntima de cada uma delas - ao centro que lhes possibilita ser o que são: uma disciplina -, pois é pelo rompimento das fronteiras disciplinares que se chega "ao que ainda não foi visto nem dito [...]. Traçar linhas de fuga para o que é estranho, para o que não tem correspondência, para o que escapa, e que, por escapar, constitui a materialização mesma das forças que transformam." (AMADOR, 2015, p. 232).

Santomé (1998) auxiliou a diminuir a sensação de complexidade que gira em torno das ideias apresentadas acima, ao afirmar que não se pretende desvalorizar o 
conhecimento encapsulado e guardado nos diferentes campos disciplinares, pois, para que aconteça a comunicação dos conceitos e procedimentos entre as disciplinas, torna-se necessária a existência delas, para que as propostas interdisciplinares possam se apoiar nas mesmas. Além disso, quanto maior for o desenvolvimento científico obtido pelas disciplinas, elas serão marcadas e influenciadas pelo nível de colaboração dado à interdisciplinaridade.

Este estudo buscou desenvolver dois conceitos essenciais: interdisciplinaridade e estratégias didáticas. Para encaminhar o primeiro, foi escolhido Zabala, que apresenta a interdisciplinaridade como sendo "a interação entre duas ou mais disciplinas que pode ir desde a simples comunicação de ideias até a integração recíproca dos conceitos fundamentais e da teoria do conhecimento, da metodologia e dos dados da pesquisa" (ZABALA, 1998, p. 143). Santomé (1998, p. 73) complementa que este grau de relação disciplinar implica um compromisso e uma vontade de partir do contexto geral, dando espaço para cada disciplina interagir com a outra, resultando em uma intercomunicação com modificações nos conceitos, nas metodologias de pesquisa e nas terminologias fundamentais. Neste caso, há uma troca recíproca entre as diferentes disciplinas e "um equilíbrio de forças nas relações estabelecidas" (SANTOMÉ, 1998, p. 73). Santomé esclarece ainda que

O ensino baseado na interdisciplinaridade tem um grande poder estruturador, pois os conceitos, contextos teóricos, procedimentos, etc. enfrentados pelos alunos encontram-se organizados em torno de unidades mais globais, de estruturas conceituais e metodológicas compartilhadas por várias disciplinas (SANTOMÉ, 1998, p. 73).

Lenoir e Hasni (2016) explicam o conceito de interdisciplinaridade escolar, quando duas disciplinas ou mais estão em relação, na dimensão curricular, cognitiva e operacional, para estabelecer uma complementação, uma cooperação entre as disciplinas envolvidas e seus respectivos pontos de vista sobre o objeto do conhecimento.

Fazenda $(2012,2013)$ aprofunda a interdisciplinaridade e afirma que ensinar e aprender por um currículo dividido em disciplinas só aumenta a quantidade de 
informações recebidas pelo sujeito, sem, entretanto, desenvolver um olhar mais amplo, mais relacional, necessário a todos os sujeitos atualmente. Os centros da interdisciplinaridade, para Fazenda, são o sujeito aluno, o sujeito professor e o conhecimento. A educação e a integração dos conhecimentos preenchem a demanda pela aprendizagem interdisciplinar e por um ensino igualmente interdisciplinar.

Antes de explorar o conceito de estratégia, é importante esclarecer que há controvérsias ou complementaridades entre os autores ao definir este conceito. Segundo Roldão (2009), ainda hoje, de forma equivocada, define-se estratégia como uma possibilidade de ações: trabalhos em grupo, fichas, leitura e produção de textos, produção de cartazes, uso de diferentes dispositivos, apresentações de trabalhos. As sugestões, presentes nos vários manuais voltados à prática do professor, empobrecem a responsabilidade daquele que deve ser o responsável por fazer o outro aprender. Para Anastasiou e Alves (2009), as estratégias devem estar relacionadas aos princípios presentes em um Projeto Político-Pedagógico, nas concepções de sujeito, de ensino e aprendizagem vividas por uma instituição educacional. Para esses autores, o professor deve ser "um verdadeiro estrategista [...] no sentido de estudar, selecionar, organizar e propor as melhores ferramentas facilitadoras para que os estudantes se apropriem do conhecimento." (ANASTASIOU; ALVES, 2009, p. 76).

Roldão (2009) confirma as ideias anteriores, pois, segundo ele, no ato de ensinar, o conceito de estratégia refere-se a uma ideia ampla e global, que revela uma concepção concretizada em ações. Nesse estudo, considera-se que o conceito de estratégia tem um sentido amplo e refere-se mais a um comportamento estratégico do professor, um pensamento ou postura estratégica e menos aos tipos de atividades que são propostas ao estudante, para se aproximar dos objetivos pretendidos. Portanto, quando o estudo propõe identificar estratégias com perspectivas interdisciplinares, o significado dado é de "uma aç̧ão especializada em promover, intencionalmente, a aprendizagem de alguma coisa por outros." (ROLDÃO, 2009, p. 55). O elemento intencionalidade é revelador de qual concepção está oculta na ação de quem promove a aprendizagem do outro, influenciando o conjunto de ações que, se concretizadas, podem causar aprendizagens adequadas e objetivos atendidos. 
Em síntese, o sentido dado à estratégia pode representar um conjunto de ações fragmentadas, executadas com o sujeito aprendente, sendo essenciais para concretizar os princípios e concepções adotados por aquele que ensina, mas, além disso, implica também em assumir uma determinada postura estratégica, revelada na forma em que as ações definidas serão executadas durante o ato de ensinar do professor.

\section{Campo de pesquisa e população-alvo}

Como já foi mencionado anteriormente, os estudantes observados foram aqueles do 6o semestre do curso de Pedagogia, justificando-se a escolha pelo fato de este grupo estar sendo preparado para formar-se professor há cinco semestres, na mesma instituição, tendo em geral os mesmos professores durante esse tempo. Destaca-se, novamente, o fato de a pesquisadora ser uma das professoras do grupo de alunos, estando, assim, pesquisadora e formadora articuladas na mesma pessoa, o que pode ter causado uma fragilidade na interpretação dos resultados, desdobramento que não foi previsto no projeto inicial.

A observação aconteceu nas aulas de quatro componentes curriculares, ${ }^{4}$ e os dados foram obtidos aplicando-se os seguintes instrumentos: I. Grelha de observação das aulas, que definiu os objetivos da observação, as dimensões (sujeitos observados) e os pontos a observar, neste caso, as estratégias e/ou atividades propostas pelos formadores; II. Guião questionário, instrumento usado para transformar em dados as informações comunicadas por outras pessoas, sem utilizar a observação direta dos fenômenos.

\section{Apresentação dos resultados}

O instrumento questionário dialogou com os alunos por meio de três questões provocadoras com o mesmo objetivo: conhecer quais estratégias de aprendizagem eram escolhidas pelos alunos e como justificavam suas escolhas. Eis as questões aplicadas:

\footnotetext{
${ }^{4}$ Em duas das disciplinas, a pesquisadora também era professora do grupo.
} 
I. Sabendo agora deste conceito [estratégia], você considera que as estratégias utilizadas pelos professores nas aulas contribuem/contribuíram para a sua aprendizagem? Justifique a resposta.

II. Qual(is) estratégia(s) utilizada(s) pelos professores, durante o curso de Pedagogia, contribuiu ou contribuíram para que você aprendesse melhor? Justifique.

III. Você consegue relatar alguma aula/atividade/estratégia proposta pelos professores, durante o curso de Pedagogia, que teve um significado para você? Justifique.

Os resultados obtidos foram agrupados por semelhança e mostram como os alunos fizeram suas escolhas:

I. estágio curricular e pautas de observação (11,85\%);

II. discussões em sala (11,85\%);

III. diferentes estratégias $(17,39 \%)$.

Os dados evidenciam também que $97,8 \%$ dos estudantes consideraram que as estratégias colaboram para:

I. melhores aprendizagens;

II. apreensão dos conteúdos sem memorizá-los (entendeu-se que foi com a compreensão dos conteúdos);

III. potencialização das aprendizagens.

As respostas registradas referem-se às lembranças de atividades significativas, ações e experiências propostas pelos professores. Há evidências nas justificativas escritas de que, ao realizar as propostas de atividades, os alunos obtiveram melhores aprendizagens. Com certeza, eles não se referiam ao conceito de estratégia no sentido de uma concepção ampla, relacionada a um comportamento estratégico dos professores, pois, na solicitação, a representação de estratégia sugeria a ideia de atividades realizadas. De acordo com Roldão (2009), o termo estratégia não é sinônimo de atividade ou tarefa, embora precise delas para ser operacionalizado. Esse autor afirma que uma atividade ou tarefa pode servir a estratégias diferentes, a depender da finalidade e da concepção definidas pelo 
professor. Entretanto, afirma-se que os resultados expressaram várias atividades propostas pelos professores em semestres anteriores, mas, interpretando as vozes dos estudantes, percebeu-se que, na visão do aluno, houve aprendizagem, portanto há indícios da presença de uma intencionalidade do professor na escolha da proposta, possivelmente relacionada aos objetivos da(s) disciplina(s) envolvida(s).

Quanto ao conceito de interdisciplinaridade, os dados obtidos com a aplicação do questionário mostraram que o estudante faz relações:

I.entre teoria e prática nas disciplinas de estágio curricular;

II. entre os conteúdos das disciplinas (sem especificação de nenhum deles em particular);

III. entre estudos de caso apresentados e o estágio;

IV. entre os conteúdos do curso e as práticas vividas na escola em que atuam.

Os alunos justificaram que as discussões em grupo e as rodas de conversa favoreceram as aprendizagens, bem como ouvir a experiência dos colegas e as trocas entre professor e aluno. As pautas de estágio orientaram os alunos nas observações realizadas nas escolas. Estagiar como observador e entrevistar atores das instituições são atividades que geram informações, e quando essas observações retornam à sala, o professor formador, com sua prática, pode mediar um diálogo entre as pessoas, entre os conhecimentos, articulando os saberes da própria disciplina da qual é responsável.

A socialização de estágio, enquanto prática realizada no interior de cada disciplina, não constitui uma atividade interdisciplinar, pois os dados não mostram, objetivamente, o envolvimento de mais de uma disciplina, embora seja uma atividade que permeie todos os componentes curriculares com estágio. Em síntese, os resultados alcançados pela aplicação do questionário foram significativos para esta pesquisa, considerando-se as opiniões positivas dos estudantes em relação à prática do estágio e à socialização das observações nas rodas, pois mostraram o quanto contribuíram para as aprendizagens e para o exercício da relação entre teoria e prática, não havendo nenhuma voz (de aluno) contrária a essa afirmação. 
Entretanto, não se pode afirmar que as propostas colocadas pelos professores e relatadas pelos estudantes tenham alguma perspectiva interdisciplinar. Leite et al. (2013) entendem que há níveis de interdisciplinaridade pelo rompimento das fronteiras das disciplinas, mas, quando se cultiva uma atitude interdisciplinar nos estudantes e no professor e há uma consciência das possibilidades de abertura que o currículo escolar permite, é possível acontecer uma formação interdisciplinar por meio dos procedimentos de estágio, comuns entre as diferentes disciplinas, e do uso igualmente comum de algumas estratégias didáticas, tais como seminários, palestras, trabalhos em grupo, estudo de caso e situação-problema.

Mangain, Dufour e Fourez (2002, p. 71) afirmam que a interdisciplinaridade exige mais que a "importação de conceitos, metodologias, competências", pois sua essência consiste em recorrer a diversas disciplinas para elaborar a representação de uma situação real, de um problema, de forma simplificada, sem desvalorizar essa simplificação, desde que "respeitando certos critérios de validade, ela permite apreender melhor um estado do real, em função de um contexto e de um projecto determinados" (MANGAIN; DUFOUR; FOUREZ, 2002, p. 71).

Quanto à Grelha de observação das aulas, ela foi planejada para coletar dados sobre:

I. a interação do estudante com a proposta e com o próprio professor, mediada pela estratégia e/ou atividade;

II. as situações e/ou estratégias propostas pelo professor formador.

É fundamental esclarecer que a prática pedagógica dos professores observados não foi objeto de crítica e nem de comparação entre eles. O foco foi a proposta realizada em aula ou colocada como atividade fora da sala.

Analisando-se os resultados, percebeu-se que as propostas foram facilitadoras do diálogo entre aluno e professor e concederam espaço para a participação dos estudantes, valorizando a voz do aluno, seja na socialização de uma pauta de estágio ou em uma atividade em grupo, ou ainda na exposição oral e dialogada de um conteúdo. Fazenda (2004) afirma que um dos indicadores da interdisciplinaridade é a presença do diálogo 
para garantir uma articulação entre teorias (conceitos e procedimentos) e a prática profissional.

Os resultados registrados na grelha expressam que cada formador trabalhou de forma isolada, desenvolvendo os objetivos propostos para sua disciplina. Embora alguns (ou vários) objetivos sejam comuns e dialoguem com os documentos institucionais, a inexistência de um tempo coletivo, intencional, sistemático para uma troca entre os professores torna inviável a possibilidade de uma ação interdisciplinar. Os autores Mangain, Dufour e Fourez (2002); Lenoir (2012); Lenoir e Hasni (2016); Fazenda (2012, 2013); Santomé (1998) e outros são unânimes em afirmar a importância do trabalho em equipe para atividades interdisciplinares, pois em grupo são realizadas negociações e parceria, trocas de experiência, construção de novas práticas pedagógicas. Pessoalmente, a autora deste estudo acredita que os professores conhecem os princípios educativos da instituição, mas não há (ou, se houver, é desconhecido) um tempo real e formal para uma discussão sobre eles. Mangain, Dufour e Fourez (2002) definem a importância de se constituir uma cultura de equipe, com uma linguagem comum, alinhavada de forma progressiva pela troca de métodos, debates sobre concepções de educação e valores. Em grupo, os professores podem vir a se interessar pelos conteúdos e objetivos das outras disciplinas, desenvolvendo ferramentas próprias para articular os saberes e métodos, colocando-os em ação, ampliando assim o autoconhecimento e as competências.

Quando acolhe a contribuição do aluno, o formador ora amplia, ora escuta ou incorpora a contribuição, relacionando-a com outros tópicos desenvolvidos. O diálogo que acontece na aula, entre estudantes e professor, possibilita que os primeiros exponham conteúdos presentes nos textos de leitura prévia, com um pensar e uma expressão livres, relacionados com o eixo do conteúdo desenvolvido. Não se observou, da parte do formador, uma sistematização clara e intencional dos objetivos conceituais e/ou procedimentais que, por exemplo, justificassem a escolha de um determinado texto ou tema de discussão. Como o estudo não contemplou outro instrumento, por exemplo, uma entrevista com cada professor, não foi possível identificar a intencionalidade que o professor teve ao propor uma determinada atividade individual ou coletiva. Portanto, não se pode afirmar que a atividade proposta em aula tenha o caráter global e amplo de 
estratégia, evidenciando uma concepção estratégica do professor ao planejar as atividades. Considera-se que a ausência de um contato maior com os professores observados, a respeito de suas intenções ao propor uma determinada atividade, deixou um vazio na pesquisa, pois não possibilitou conhecer a intencionalidade e os reais objetivos do professor, não só com a atividade proposta na aula, mas também com as demais, que a antecederam ou precederam.

Sabe-se que a pesquisadora ocupou um duplo papel nesta pesquisa, pois, ao mesmo tempo que foi observadora, trouxe dados provenientes de sua própria prática. Portanto, não seria relevante incluir a intenção da autora do texto quando planejou as atividades da disciplina sob sua responsabilidade. É possível que este fato tenha sido um aspecto complicador no estudo realizado.

Finalizando a articulação dos dados com o campo teórico, apresentam-se algumas observações:

I. Em uma das disciplinas observadas, com características de natureza mais conceitual, a participação dos alunos no diálogo com o formador deu-se em forma de perguntas e dúvidas, respondidas pelo professor com explicações conceituais e procedimentais sobre o conteúdo, com dados da realidade, na tentativa de relacionar a teoria com ações concretas do ambiente externo.

II. Os alunos apresentavam dificuldades na leitura dos textos e na compreensão dos conteúdos quando não possuíam repertório construído anteriormente em outro momento do curso. Mesmo assim, alguns estudantes estabeleciam relações com aspectos da vida pessoal e com experiências vividas nas escolas, enquanto auxiliares e/ou professores titulares.

III. O diálogo do aluno com o professor favoreceu a associação com fatos da vida pessoal e profissional, exemplos reais, situações vividas em aulas anteriores da mesma disciplina ou em outras disciplinas.

\section{Considerações finais}

Para finalizar este estudo, a autora apresenta uma citação que resume, em sua opinião, os resultados alcançados: Quem é essa autora, não ficou claro. 
As iniciativas interdisciplinares precisam ser planejadas, pois raramente obtêm resultados positivos quando conduzidas de modo impensado. Exigem uma ação estratégica que objetive as intenções. Os objetivos, as definições conceituais, os tipos de ação, o contexto institucional, tudo requer previsão. A integração, a cooperação e as inter-relações de conhecimento dependem de procedimentos adotados. (PAVIANI, 2014, p. 63)

Este autor foi escolhido para expressar as considerações sobre o estudo porque, pelos dados coletados, tanto no questionário como nos registros de observação de aula, não se pode afirmar que os professores observados tinham uma concepção estratégica interdisciplinar, uma intencionalidade de trabalhar com a interdisciplinaridade, pois não se observou o envolvimento de mais de uma disciplina em uma proposta conjunta, com perspectiva interdisciplinar. Nas reuniões semanais de formação, esta autora, enquanto participante, não teve conhecimento de discussões coletivas sobre o tema.

Entretanto, na análise das estratégias/atividades didáticas utilizadas pelos formadores observou-se que elas têm potencial para possibilitar que os estudantes estabeleçam relações entre áreas do conhecimento das disciplinas curriculares. Conclui-se que não há, da parte dos formadores, uma intencionalidade estratégica, direcionada a um ensino interdisciplinar.

Mesmo assim, os dados levantados, entrelaçados com os teóricos estudados, possibilitaram responder às perguntas iniciais e identificar se, ao menos parcialmente, os objetivos foram atendidos. ${ }^{5}$

I. As atividades/estratégias identificadas foram consideradas individualmente e de forma isolada, por isso, não evidenciaram, com clareza, se possuem uma perspectiva interdisciplinar.

\footnotetext{
${ }^{5}$ Identificar se as estratégias didático-pedagógicas utilizadas pelos professores formadores contribuem para uma aprendizagem com perspectiva interdisciplinar; e se as estratégias escolhidas e aplicadas pelos professores formadores desenvolvem nos futuros professores habilidades de relacionar, com autonomia, os conhecimentos desenvolvidos nas diferentes disciplinas, colaborando para um rompimento das fronteiras disciplinares. Quais são as principais estratégias didático-pedagógicas interdisciplinares utilizadas pelos professores formadores na formação inicial docente? Quais são as ações e as estratégias didático-pedagógicas que possibilitam a construção de um pensamento interdisciplinar, um fio condutor que ligue conteúdos que, aparentemente, circulam em paralelo?
} 
II. Os dados observados mostram que o professor formador permanece circundado por sua disciplina e pelos objetivos de aprendizagem planejados para o seu curso.

III. Os alunos afirmaram que conseguiram aprender melhor realizando as atividades propostas, portanto as atividades favoreceram melhores aprendizagens.

IV. Os alunos têm potencial para relacionar com autonomia aprendizagens (conceitos, procedimentos) e habilidades de pensamento propostas por alguns professores, de diferentes disciplinas.

Em síntese, o estudo mostrou que, se houver uma interação maior entre os professores, de forma a construírem uma concepção estratégica de interdisciplinaridade, será possível planejar uma sequência de ações com uma intencionalidade e, assim, desenvolver nos estudantes um pensamento interdisciplinar.

\section{Referências}

AMADOR, Fernanda Spanier. Transdisciplinarizar. In: FONSECA, Tania Mara Galli; NASCIMENTO, Maria Lívia do; MARASCHIN, Cleci (org.). Pesquisar na diferença, um abecedário. Porto Alegre: Sulina, 2015.

ANASTASIOU, Léa das Graças Camargos; ALVES, Leonir Pessate (org.). Processos de ensinagem na universidade: pressupostos para as estratégias de trabalho em aula. Joinville: Univille, 2009.

ANDRÉ, Marli Eliza D. A. Etnografia da prática escolar. Campinas: Papirus, 1995.

ECHEVERRÍA, Javier. A escola contínua e o trabalho no espaço-tempo eletrônico. In: JARAUTA, Beatriz; IMBERNÓN, Francisco (org.). Pensando no futuro da educação: uma nova escola para o século XXII. Porto Alegre: Penso, 2015.

FAZENDA, Ivani. Metodologia da pesquisa educacional. São Paulo: Cortez, 2004.

FAZENDA, Ivani (org.). Didática e interdisciplinaridade. Campinas: Papirus, 2012.

FAZENDA, Ivani. Práticas interdisciplinares na escola. São Paulo: Cortez, 2013. 
LEITE, Alexandre César Cunha et al. Interdisciplinaridade, práticas curriculares e formação do docente interdisciplinar. In: FAZENDA, Ivani Catarina Arantes; FERREIRA, Nali Rosa Silva (org.). Formação de docentes interdisciplinares. Curitiba: CVR, 2013.

LENOIR, Yves. Didática e interdisciplinaridade: uma complementaridade necessária e incontornável. In: FAZENDA, Ivani (org.). Didática e interdisciplinaridade. Campinas: Papirus, 2012.

LENOIR, Yves; HASNI, Abdelkrim. Interdisciplinaridade no ensino fundamental e médio: questões e perspectivas. Educação Criativa, [s. I.], v. 7, n. 16, 2016.

MANGAIN, Alain; DUFOUR, Barbara; FOUREZ, Gérard. Abordagens didácticas da interdisciplinaridade. Lisboa: Horizontes Pedagógicos, 2002.

PAVIANI, Jayme. Pedagogia Interdisciplinar. In: PAVIANI, Jayme. Interdisciplinaridade: conceitos e distinções. Caxias do Sul: Educs, 2014.

ROLDÃO, Maria do Céu. Estratégias de ensino: o saber e o agir do professor. Portugal: Fundação Manuel Leão, 2009.

SANTOMÉ, Jurjo Torres. Globalização e Campinas: o currículo integrado. Porto Alegre: Artes Médicas, 1998.

ZABALA, Antoni. A prática educativa: como ensinar. Porto Alegre: Artmed, 1998. 